九州大学学術情報リポジトリ

Kyushu University Institutional Repository

\title{
Modeling and Managing Airport Passenger Flow under Uncertainty: A Case of Fukuoka Airport in Japan
}

Yamada, Hiroaki

Fujitsu Laboratories Ltd.

Ohori, Kotaro

Fujitsu Laboratories Ltd.

Iwao, Tadashige

Fujitsu Ltd

Kira, Akifumi

Institute of Mathematics for Industry, Kyushu University

他

http://hdl. hand le. net/2324/4371069

出版情報: Social informatics : 9th International Conference. SocInfo 2017 (10540), pp.419-430, 2017-09-02. Springer

バージョン :

権利関係 : 


\title{
Modeling and Managing Airport Passenger Flow under Uncertainty:
}

\section{A Case of Fukuoka Airport in Japan}

\author{
Hiroaki Yamada ${ }^{1}$, Kotaro Ohori ${ }^{1,3}$, Tadashige Iwao ${ }^{2,3}$, Akifumi Kira ${ }^{3,4}$, Naoyuki Ka- \\ miyama $^{3,5}$, Hiroaki Yoshida ${ }^{1}$ and Hirokazu Anai ${ }^{1,3}$ \\ ${ }^{1}$ Fujitsu Laboratories Ltd., 1-1, Kamikodanaka 4-chome, Nakahara-ku, Kawasaki 211-8588, \\ Japan \\ ${ }^{2}$ Fujitsu Ltd., Shiodome City Center 1-5-2 Higashi-Shimbashi, Minato-ku, Tokyo 105-7123, \\ Japan \\ ${ }^{3}$ Institute of Mathematics for Industry, Kyushu University, 744 Motooka, Nishi-ku Fukuoka \\ 819-0395, Japan \\ ${ }^{4}$ Faculty of Social and Information Studies, Gunma University, 4-2 Aramaki-machi, Maebashi, \\ Gunma, 371-8510, Japan \\ ${ }^{5}$ JST, PRESTO, 4-1-8 Honcho, Kawaguchi, Saitama, 332-0012, Japan \\ yamadahejp.fujitsu.com
}

\begin{abstract}
Airport terminal decision makers in recent years need to deal with unexpected and sudden congestion situations. Although various types of mathematical research has analyzed the congestion situations and have succeed to manage a subsystem, they cannot sufficiently describe the variety of phenomena observed in a real airport terminal, because they have not considered the interactions between subsystems of the real airport terminal. A simulation approach enables us to describe the interactions between facilities and passenger behavior in detail as a whole airport system and to find various types of possible congestion situations. The simulation approach, however, cannot directly lead exact prediction that can be useful in practical management and operation for difficulties of modeling a complex airport terminal system and acquiring complete input data. In this paper, (1) we modeled Fukuoka airport international terminal in Japan as Complex Adaptive System and built a passenger flow simulation based on the Discrete Event Model. Validity of the simulation were confirmed by experiments. Moreover, (2) we confirmed that it is possible to get information, which is difficult to collect by observation, from discussing with stakeholders using the simulation. Therefore, we believe it is possible to reduce uncertainty of the simulation systematically by continuing modeling, predicting, and discussing with stakeholders, repeatedly.
\end{abstract}

Keywords: Passenger Flow Simulation, Airport Terminal, Complex Adaptive System, Discrete Event Model, System Design Methodology. 


\section{Introduction}

Airport terminal decision makers in recent years need to deal with unexpected and sudden congestion situations. The unexpected congestions are caused by periodic or sudden condition change, such as passenger demand [3, 14], weather and equipment behavior [16], and also unintended and emerging effects of variety of interventions conducted by multi-stakeholders [6]. In order to prevent congestions which cause delay of flights [12] and lowering of passenger's satisfaction [8], the necessity of optimizing airport terminals in space-time high resolution and from holistic viewpoint is growing.

To predict and control the congestion situations, various types of mathematical research has analyzed the change of congestion situations from the viewpoint of planning the adequate capacity of facilities based on the estimation of passenger demands [26, 32], and designing landing slot auction based on peak-load pricing [23]. Although these studies have high practicability to the planning of a specific facility of an airport terminal, most models have not considered the interactions between many facilities of the terminal. As a result, they cannot sufficiently describe the various phenomena observed in a real airport terminal. On the other hand, there is also simulation research that analyzed passenger flow and the optimal operation schedule [30]. The simulation approach enables us to describe the model of facilities and passenger behavior in detail as a whole airport system and to find various types of possible congestion situations that can be observed in the terminal. The simulation approach, however, cannot directly lead exact congestion prediction that can be useful for practical operation from the following two viewpoins: (1) modeling of a complex airport terminal system; (2) acquisition of complete input data.

The airport terminal system consists of plural subsystems such as baggage X-ray inspection facility, check-in facility, security checks facility, and departure examination facility, which are mutually connected to autonomously communicate with each other. The autonomous distributed system, which can be regarded as Complex Adaptive Systems (CAS) [17], has emergent properties such as percolation and phase transition [6, 7], and then causes various types of congestion situations due to the properties. In order to analyze practical issues in CAS, it is necessary to build a system model that can represent subsystems and the relationship among them in detail and to consider overall optimization of the whole system based on the model $[17,35]$.

The acquisition of complete input data is also a critical problem when using the simulation model for practical situation. Although the complex airport model can describe various types of situations observed in a real world, high accuracy and large amounts of input data is required to set the model parameters [23, 24]. It is difficult, however, to get complete data for setting about the model parameters from multi-stakeholders such as airlines, a security company and an airport building company at the airport terminals for the following two reasons. First, they cannot understand the effectiveness of simulation technique as a solution for reducing congestion without the explanation of simulation results. Second, they have high cost efforts in confirming their regulation relevant to information management so as to take the information outside. Hence, we need to consider a novel approach to gain the data for building a complex simulation model in multi-stakeholders situations. 
The purposes of this paper are (1) to build an airport terminal model that has the features of CAS with appropriate level of abstraction, and (2) to consider a data collection process which systematically reduces the lack or the error of simulation input data through communication with multi-stakeholders in the airport.

\section{$2 \quad$ Modeling and Managing Strategy}

We select Fukuoka Airport International Terminal (FUK int'l terminal), which has the feature of CAS explained in the previous section, in Japan as a target field. This section describes a problem situation in FUK int'l terminal, and then states our research strategies for (1) building a FUK int'l terminal model in an appropriate level of abstraction and (2) collecting real data to input the model parameters systematically.

Fukuoka Airport is the third-largest airport after Haneda Airport and Narita International Airport in Japan, and has 20 million passengers per year in 2014. The number of inbound travelers is rapidly growing and congestion become serious. The terminal departure floor consists of baggage X-ray inspection facility, security checks facility, check-in facility, and departure examination facility. An airport security company operates the X-ray inspection and security checks facilities, airline companies and the immigration bureau controls the check-in and departure examination facilities, respectively. So each stakeholder is required to handle passenger flow autonomously in bottom-up management rather than top-down one, and then the whole system including the facilities has the feature of CAS. Since there are multi-stakeholders who have various types of information that cannot be opened to other ones due to the restriction of security and information system, it is difficult for each stakeholder to understand the congestion situation of facilities managed by other stakeholders. Thus the passengers adopt homogenous behavior without autonomous decision-making processes, however, the passengers have different time for each procedure based on their passenger characteristics such as nationality, boarding flight and boarding class (see Appendix 1). For example, the passengers who ride on LCC carriers mainly consist of some tourist groups with many baggage items, while legacy carriers have a number of business passengers who have few baggage and travel by themselves. The different proportion of each passenger characteristic, which changes dynamically depending on the flight schedule and seasonal characteristics, generates various types of congestion behavior which is difficult to predict accurately in practical management.

To analyze the problem situations, we build the model of FUK int'l terminal departure floor. There have been various types of case studies that tried to analyze queuing behavior of customers based on a basic mathematical models, consists of the arrival process of customers, the mechanism of service facilities and the rule of choosing customers from a queue $[1,18,26,33]$. Dunlay \& Park [9] provided the queueing network model that can represent the structure of a series of service procedures in multiple facilities of FUK int'l terminal departure floor. However the queuing models cannot consider individual heterogeneity in detail and accordingly, they cannot describe complex congestion behavior generated by the different types of passengers of our concern. On 
the other hand, simulation research with an individual model can represent the heterogeneity of passengers [11]. The simulation research is mainly classified into discrete event simulation (DES) and agent-based simulation (ABS) [5]. DES can represent that heterogeneous entities $[11,19]$, which do not have decision making capability, behave in pre-determined process, while ABS enable us to describe complex micro or individual level decision making and interactions in detail [13, 20, 27, 31]. The passengers in FUK int'l terminal departure floor, advance in the pre-determined procedures, but have heterogeneous characteristics that affect the procedure time in each facility. Therefore, we select DES for building our model that represents facilities and passengers in FUK int'l terminal departure floor.

Next we explain the research process to consider the methodological issue to acquire complete data for the model parameters settings. As one of effective ways, in order to collect data for simulation models automatically, sensing devices have been examined $[15,21]$. However, it is difficult to introduce the devices into FUK int'l terminal for developing the model due to cost and security related restrictions. As we explained in Section 1, we therefore need to acquire the data from multi-stakeholders who have enough domain knowledge about own facilities and passengers. Ohori et. al. [28, 29] pointed out the communication with stakeholders through the simulation results is useful to extract their domain knowledge efficiently. We also focus on the usage of the simulation as communication tool, and then gradually extract the knowledge from them while repeating presentation of simulation analyses with various settings. As a result, we will be able to collect the complete data for model parameters, and thus to predict congestion situation exactly in the multi-stakeholder situations.

\section{$3 \quad$ Model}

We model all facilities and all passengers of the FUK int'l terminal departure floor based on the Discrete Event Model. There are four types of facilities which passengers are needed to pass, baggage X-ray inspection, check-in, security check, and departure examination. Baggage X-ray inspection, check-in, security check, and departure examination consists of several number of unit or counter. And a check-in counter consists of several number of booths. The passenger has to pass those facilities. The counter or the booth the passenger uses is predetermined by his/her flight. The time being needed to pass depends on number of people or number of baggage. If the passenger has more than one available the counters or the booths, his/her choose not congested one. If a counter or booth is closed, the passenger queuing there goes another counter or booth. Passengers who are member of tour group exhibit unique behavior. They arrive at the airport at the same time, because they board same tour bus. They pass the baggage Xray inspection and the check-in individually. After that, they pass the security check with other tour member. Namely, they wait other tour member in front of the security check. This situation is represented by a Queueing Network and the parameters' values are collected by variety of ways (see Appendix 2).

The baggage X-ray inspection facility $B_{n}\left(B_{-} p_{n}, B_{-} s_{n}\right)$ has 2 parameters: processing speed $B_{-} p_{n}$ is the time being needed to inspect one baggage, operation schedule $B_{-} s_{n}$ 
is the timetable about operation or non-operation. The check-in facility $C_{n m}\left(C_{-} c p_{n m}, C_{-} b p_{n m}, C_{-} s_{n m}, C_{-} t_{n m}\right)$ has 4 parameters: check-in processing speed $C_{-} c p_{n m}$ is the time being needed making one person check-in. baggage processing speed $C_{-} b p_{n m}$ is the time being needed making one baggage check-in. operation schedule $C_{-} s_{n m}$ is the same as the baggage facility model's one, passenger type $C_{-} t_{n m}$ represents the booth for business class or the booth for economy class. The security check facility $S_{n}$ has 2 parameters $S_{n}\left(S_{-} p_{n}, S_{-} S_{n}\right)$ and the departure examination facility $E_{n}$ has 2 parameters $E_{n}\left(E_{-} p_{n}, E_{-} s_{n}\right)$. Those parameters are the same as the baggage $\mathrm{X}$-ray inspection facility. $n$ is unit number or counter number. A check-in counter consists of several number of booths, so $m$ is booth number of counter $n$.

A group of passengers, such as a family or a group of friends etc, is a unit of passenger model. A group $G_{i}$ has 7 parameters $G_{i}\left(G_{-} f_{i}, G_{-} a_{i}, G_{-} p_{i}, G_{-} c o b_{i}, G_{-} c i b_{i}, G_{-} s_{i}, G_{-} t_{i}\right):$ boarding flight $G_{-} f_{i}$, arrival time at terminal $G_{-} a_{i}$, number of people $G_{-} p_{i}$, number of carry-on baggage $G_{-} c o b_{i}$, number of check-in baggage $G_{-} c i b_{i}$, type of seat (economy class passengers or business class passengers) $G_{-} s_{i}$, and member of tour group or not $G_{-} t_{i}$. The groups are generated by each flight. A flight $F_{j}$ has 11 parameters $F_{j}\left(F_{-} e a_{j}, F_{-} b a_{j}, F_{-} e p_{j}, F_{-} b p_{j}, F_{-} e g_{j}, F_{-} b g_{j}, F_{-} e c o b_{j}, F_{-} b c o b_{j}, F_{-} e c i b_{j}, F_{-} b c i b_{j}, F_{-} t_{j}\right)$ : arrival time distribution of economy passengers $F_{-} e a_{j}$ and business one $F_{-} b a_{j}$, number of economy passengers $F_{-} e p_{j}$ and business one $F_{-} b p_{j}$, group size distribution of economy passengers $F_{-} e g_{j}$ and business one $F_{-} b g_{j}$, distribution of number of carryon baggage of economy passengers $F_{-} e c o b_{j}$ and business one $F_{-} b c o b_{j}$, distribution of number of check-in baggage of economy passengers $F_{-} e c i p_{j}$ and business one $F_{-} b c i p_{j}$, and the number of tour group $F_{-} t_{j} . i$ is group number and $j$ is flight number.

\section{$4 \quad$ Experiment}

\subsection{Experiment 1}

Outline. The experiment was conducted on every morning of February 21, 22, and 23, 2017. On Feb. 21, we predicted queue lengths, on Feb. 21 and 22, we predicted queue lengths and adjusted security check facility's schedule based on simulation result. The temporal variation of those facilities' queue lengths was measured. We use $95 \%$ prediction interval to evaluate predictability of the model. Prediction rate is defined by rate of the sample points correctly predicted by $95 \%$ prediction interval.

Result. Table 1 is the result of experiment. The check-in have been well predicted, on the other hand, baggage X-ray inspection and security checks have been mis-predicted.

Table 1. The result of experiment 1.

\begin{tabular}{llll}
\hline & Feb. 21 & Feb. 22 & Feb. 23 \\
\hline Baggage X-ray inspection & $57.81 \%$ & $52.12 \%$ & $52.12 \%$
\end{tabular}




\begin{tabular}{clll} 
Check-in & $80.99 \%$ & $84.11 \%$ & $83.33 \%$ \\
Security check & $33.02 \%$ & $46.67 \%$ & $37.46 \%$ \\
\hline
\end{tabular}

Analysis. We hypothesized that the mis-prediction on the security check caused by seasonal difference of processing speed. Passengers wear coats only in winter season, thus additional operation time is required on security check compared with summer season. We observed two additional actions: inspectors direct passengers to remove coats, after that the passengers remove their coats.

Table 2 is the simulation result considering seasonal difference of processing speed. Figure 1 is temporal variation of queue length of a counter. An unpredicted peak has become replicating. The result implies that seasonal difference of processing speed causes mis-prediction. Heidt \& Gluchshenko [16] pointed out that change of equipment behavior causes change of congestion situation.

Table 2. The result of the without and with seasonal difference simulation.

\begin{tabular}{cccc}
\hline & Feb. 21 & Feb. 22 & Feb. 23 \\
\hline Without seasonal difference $(\lambda=1 / 13)$ & $33.02 \%$ & $46.67 \%$ & $37.46 \%$ \\
With seasonal difference $(\lambda=1 / 17)$ & $56.61 \%$ & $79.68 \%$ & $74.60 \%$ \\
\hline
\end{tabular}

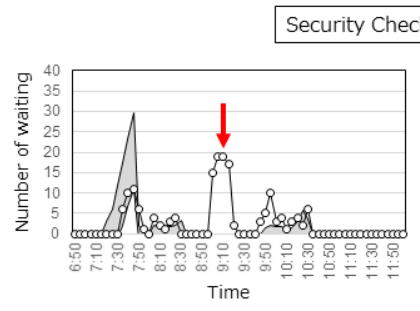

Without considering seasonal difference

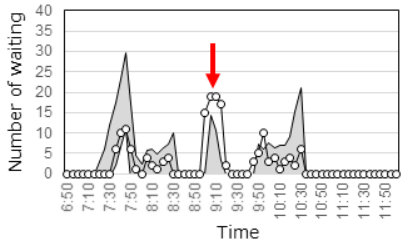

With considering seasonal difference

Fig. 1. Temporal variation of queue length of a counter. Grey area is $95 \%$ prediction interval, solid lien is the measured value.

Discussion with stakeholders. We discussed with a security company manager and airport building company managers based on the result. As a result of the discussion, the stakeholders recognized the importance of the security check processing speed data, and they promised measuring processing speed and providing it for experiment 2 .

\subsection{Experiment 2}

Outline. The experiment was conducted on April 12, 2017 morning. We predicted and measured queue length of the security check. There are two differences in Experiment 2 from Experiment 1: (1) Using actually processing speed of the security check counters $(\lambda=1 / 14,1 / 14,1 / 38,1 / 18,1 / 14)$. The data were collected from March 31, 2017 to April 
11, 2017, (2) A full-body scanner, which conducts security check automatically, was introduced. A security check units was replaced by a full-body scanner on March 31 .

Result. Figure 2 is the result of experiment 2 . The predictability has been increased.

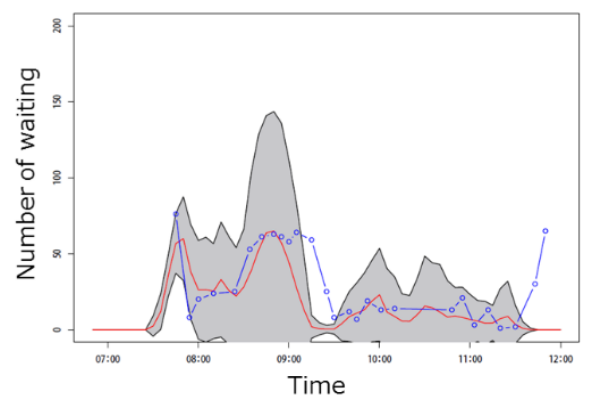

Fig. 2. The result of experiment 2. Grey area is $95 \%$ prediction interval, line (red) is average of the simulation of 100 trials, and line with points (blue) is the measured value.

Discussion with stakeholders. In order to extract experts' domain knowledge, we conducted discussion with the security company manager.

Through the discussion, it is revealed that there are 10 factors causing irregular congestion. (1) Variation of Check-in speed is different for airlines, (2) Check-in speed is different for flights, (3) Check-in speed is different for staffs, (4) Check-in speed is different for passenger types, (5) Queue formation rule in check-in is different for flights, (6) Check-in schedule is variable, (7) Security check speed is different for staffs and seasons, (8) Passenger nationality is different for seasons, (9) Passenger behavior is different for flights, and (10) Number of passenger depends on travel campaigns.

Additionally, it is revealed that the manager has a way controlling above uncertainties. The manager controls uncertainties by a simple strategy: "planning based on the worst scenario, operating for cost reduction". The following is a planning and operating process adopted in practical situation. (i) The airport building and the airlines make flight plan in summer and winter. (ii) The security check manager estimates maximum number of passengers arriving at each time from departure time and number of seats, which are contained flight plan. And the manager makes schedule every month based on the estimated maximum passengers. (iii) The manager conducts everyday operation based on the schedule. But, if excess of the processing capacity becomes clear, the manager closes surplus facilities in the time. This simple strategy reduces the personnel cost, besides suppresses disturbance from uncertainties.

\section{Discussion}

The information and knowledge gotten from the discussion with stakeholders is unknown in advance. On the process gathering those information and knowledge, we 
found two remarkable phenomena in the discussion with stakeholders: facilitating cooperation and externalizing tacit knowledge. In the experiment 1 , the stakeholders could make collective decision to cooperate for gathering processing data by the discussion using the simulation. In the experiment 2 , the manager could externalize own tacit knowledge, 10 uncertainties factors and the strategy of controlling uncertainties, by the discussion using the simulation.

In the CAS, deciding and acting for new project is difficult, because, there is no one having authority, responsibility, and resource to accomplish the project [36]. By those organizational features, the stakeholders overestimate coordination costs and hesitate to take the information outside. On the other hand, discussion using explicit model and concrete results provide "sharable focal point" to perceive problem situation and costbenefit of cooperation. If the problem and the necessity is obvious to every stakeholders, decision to cooperate becomes easy. In the CAS, it is also difficult for stakeholders to understand overview of the whole system [37]. Therefore the stakeholders can not recognize what is important information, what is unique domain knowledge, and which they have to provide it. Moreover, they are not familiar with system thinking. Explicit model and concrete results provide "mental model" to externalize experts' tacit knowledge. It is easier for experts to point out mistakes of model or parameter sets than express the correct situation from scratch.

We propose a system design methodology to develop a simulation of complex system and in multi-stakeholders situation. Under such situation, generally we cannot get enough knowledge and information because of organizational and social problems. Therefore, we need develop not only simulation but also stakeholders. We consider that by continuing modeling, simulating, and discussing repeatedly, it is possible to change technological and social aspect mutually (Figure 3).

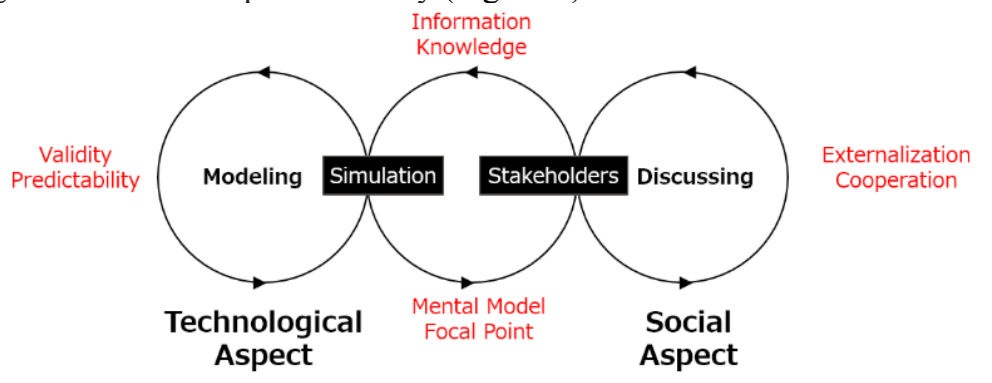

Fig. 3. Schematic view of design process of the simulation.

\section{Acknowledgement}

We appreciate to Fukuoka Airport Building Co., Ltd. for useful comments and considerable efforts. We are grateful to Mr. Daisuke Sunada and Mr. Kazuhiro Tokiwa for developing a simulator implemented our model. Naoyuki Kamiyama was supported by JST PRESTO Grant Number JPMJPR14E1, Japan. Akifumi Kira was supported in part by JSPS KAKENHI Grant Numbers 26730010 and 17K12644. 


\section{Appendix 1}

In this appendix, we describe detail of the problem situation. Figure 4 is passengers flow and management organizations of Fukuoka airport international terminal (FUK int'l terminal) departure floor in Japan. The baggage X-ray inspection consists of 6 inspection units, the check-in consists of 12 check-in counters and each counter having 8 booths, the security check consists of 5 inspection units, and the departure examination consists of 3 counters. The departure floor roughly divide in north area and south area. North-units of baggage X-ray inspection and from A counter to F counter of check-in are placed in north area. South-units of baggage X-ray inspection and from $\mathrm{G}$ counter to $M$ counter of check-in are placed in south area. Each check-in counter are managed by each airline, and the passengers use own flight counter. The check-in booth is assigned for business class passenger or economy class passenger. If the passengers use north area check-in counter, they have to use north-units of baggage X-ray inspection. It is the same in the south area. The security checks counters and departure examinations are used by all passengers freely.

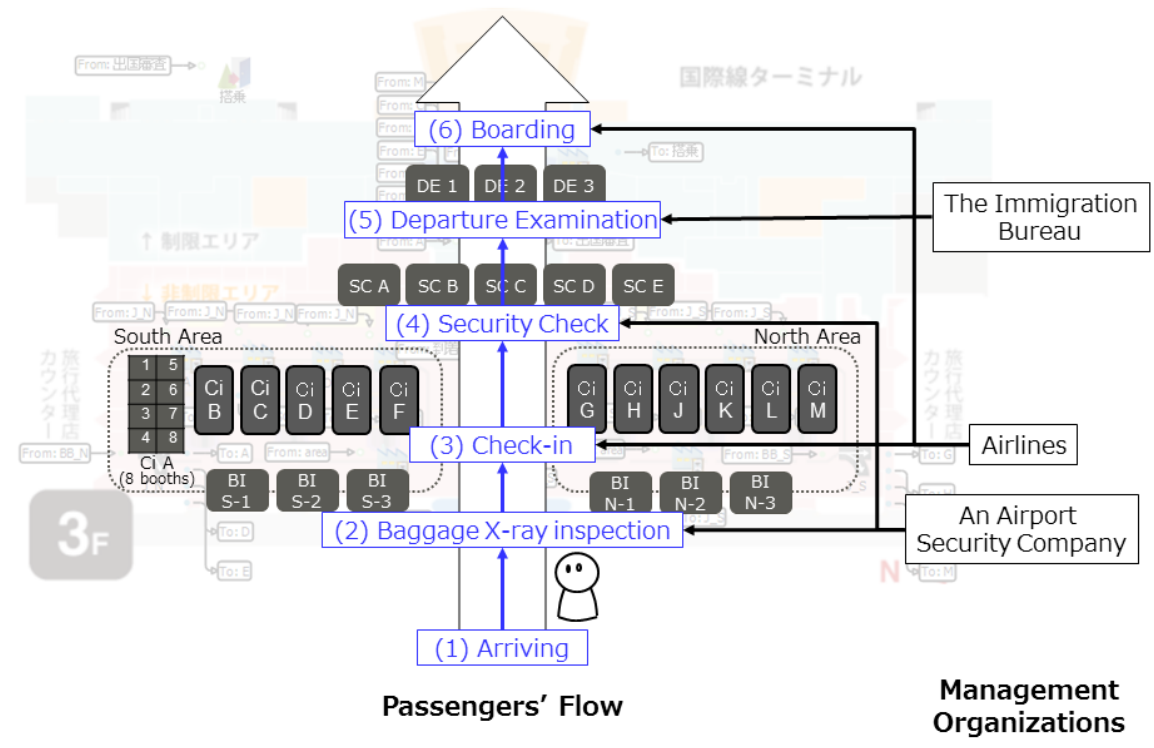

Fig. 4. Passengers' flow and management organizations of FUK int'l terminal departure floor.

The boarding process at the terminal departure floor is composed of the following steps: a passenger (i) has the examination of his/her check in baggage at the baggage X-ray inspection facility; (ii) checks in at the airport counter facility; (iii) gets the inspection of his/her body and carry-on baggage at the security checks facility; (iv) gets the inspections of his/her passport and flight ticket at departure immigration facility; and (v) proceeds to the boarding gate of his/her flight. In particular, most of passengers advance from the steps (i) to (iv) directly without visiting other facilities such as a restaurant and an exchange counter. 


\section{Appendix 2}

In this appendix, we describe detail of the model. Figure 5 is FUK int'l terminal departure floor represented by the Queueing Network. In this paper, we analyze only baggage $\mathrm{X}$-ray inspection, check-in, and security checks. Because data about the departure examination could not be gathered for security reasons.

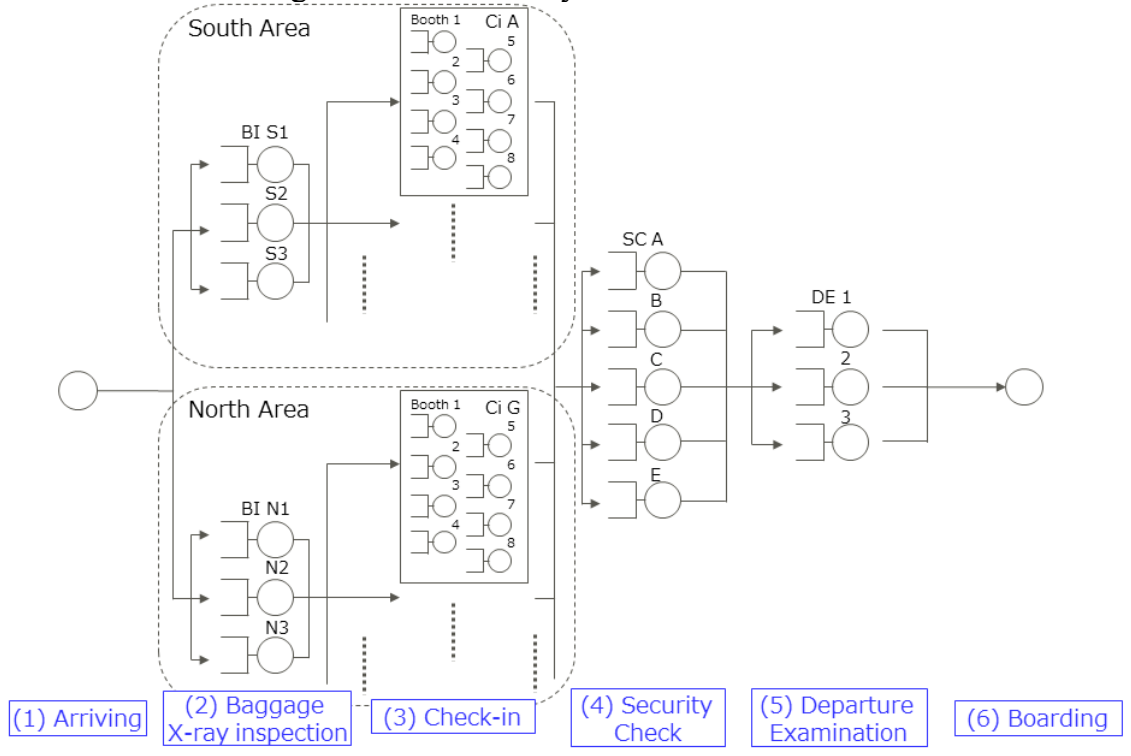

Fig. 5. FUK int'l terminal departure floor represented by the Queueing Network.

Table 3 and Table 4 are values, source of values, and collected date of the each parameter.

Table 3. The values of the facilities' parameters.

\begin{tabular}{|c|c|c|c|}
\hline Parameter & Value & Source of data & Date of collection \\
\hline$B \_p_{n}$ & $\begin{array}{l}\text { Exponential distribution } \\
(\lambda=1 / 25)\end{array}$ & $\begin{array}{l}\text { Report from a } \\
\text { manager. }\end{array}$ & Summer of 2015. \\
\hline $\begin{array}{l}C_{-} c p_{n m} \\
C_{-} b p_{n m}\end{array}$ & $\begin{array}{l}\text { Exponential distribution ( } \lambda \\
\text { is different for each airline) }\end{array}$ & $\begin{array}{l}\text { Counted pro- } \\
\text { cessing speed }\end{array}$ & Summer of 2016. \\
\hline$S_{-} p_{n}$ & $\begin{array}{l}\text { Exponential distribution } \\
(\lambda=1 / 13)\end{array}$ & $\begin{array}{l}\text { Report from a } \\
\text { manager. }\end{array}$ & Summer of 2015. \\
\hline $\begin{array}{l}B_{s_{n}}, C_{s_{n m}} \\
C_{-} t_{n m} S_{-} s_{n}\end{array}$ & Operation schedule & $\begin{array}{l}\text { Actual opera- } \\
\text { tion schedule }\end{array}$ & $\begin{array}{l}\text { About a month be- } \\
\text { fore }\end{array}$ \\
\hline$E \_p_{n}, E \_s_{n}$ & Not collectable & --- & --- \\
\hline
\end{tabular}

Table 4. The values of the flight's parameters.

\begin{tabular}{llll}
\hline Parameter & Value & Source of data & Date of collection \\
\hline
\end{tabular}




\begin{tabular}{clll}
\hline$F_{-} e a_{j}, F_{-} b a_{j}$ & $\begin{array}{l}\text { Estimated distri- } \\
\text { bution }\end{array}$ & Counted queue length & Summer of 2016. \\
$F_{-} e p_{j}, F_{-} b p_{j}, F_{-} t_{j}$ & $\begin{array}{l}\text { Number of res- } \\
\text { ervations }\end{array}$ & Reservation data & The day before \\
$F_{-} e g_{j}, F_{-} b g_{j}$, & $\begin{array}{l}\text { Empirical distri- } \\
\text { bution }\end{array}$ & $\begin{array}{l}\text { Interview and ques- } \\
\text { tionnaire to airport } \\
F_{-} e c o b_{j}, F_{-} b c o b_{j},\end{array}$ & Summer of 2015. \\
$F_{-} e c i b_{j}, F_{-} e c i b_{j}$ & & managers & \\
\hline
\end{tabular}

\section{References}

1. Barbo, W.A., (1967), The Use of Queuing Models in Design of Baggage Claim Areas at Airports. Graduate Report. Institute of Transportation and Traffic Engineering, University of California, Berkeley.

2. Baxter, G., \& Sommerville, I. (2011). Socio-technical systems: From design methods to systems engineering. Interacting with Computers, 23(1), 4-17.

3. Beria, P., \& Laurino, A. (2016). Determinants of daily fluctuations in air passenger volumes. The effect of events and holidays on Milan Malpensa airport. Journal of Air Transport Management, 53, 73-84.

4. Bødker K., Kensing F., Simonsen J., (2004), Participatory IT Design: Designing for Business and Workplace Realities, MIT Press, Cambridge.

5. Borshchev A, Filippov A, (2004): From System Dynamics and Discrete Event to Practical Agent-Based Modeling: Reasons, Techniques, Tools. In Proceedings of the 22nd International Conference of the System Dynamics Society. Oxfort, England.

6. Bouarfa, S., Blom, H. A., Curran, R., \& Everdij, M. H. (2013). Agent-based modeling and simulation of emergent behavior in air transportation. Complex Adaptive Systems Modeling, 1(15), 1-26.

7. Cook, A., Blom, H. A. P., Lillo, F., Mantegna, R. N., Miccichè, S., Rivas, D., ... Zanin, M. (2015). Applying complexity science to air traffic management. Journal of Air Transport Management, 42, 149-158.

8. Correia, A. R., Wirasinghe, S. C., \& de Barros, A. G. (2008). Overall level of service measures for airport passenger terminals. Transportation Research Part A: Policy and Practice, 42(2), 330-346.

9. Dunlay, W.J., Park, C.H. (1978). Tandem-queue algorithm for airport user flows. Transportation Engineering Journal of ASCE 104 (TE2), 131-149.

10. Drăgoicea, M., e Cunha, J. F., \& Pătraşcu, M. (2015). Self-organising socio-technical description in service systems for supporting smart user decisions in public transport. Expert Systems with Applications, 42(17-18), 6329-6341.

11. Eilon, S., Mathewson, S. (1973). A simulation study for the design of an air terminal building. IEEE Transactions on Systems, Man and Cybernetics 3 (4), 308- 317.

12. Eurocontrol, (2009). Impact Study of Landside Elements on Airport Capacity and Delays.

13. Fayez, M. S., Kaylani, A., Cope, D., Rychlik, N., \& Mollaghasemi, M. (2008). Managing airport operations using simulation. Journal of Simulation, 2, 41-52.

14. Gillen, D., \& Hasheminia, H. (2013). Estimating the demand responses for different sizes of air passenger groups. Transportation Research Part B: Methodological, 49, 24-38.

15. Gongora, M., Ashfaq, W., (2006), Analysis of passenger movement at birmingham international airport using evolutionary techniques. In: IEEE Congresson Evolutionary Computation (CEC), pp. 1339-1345. 
16. Heidt, A., Gluchshenko, O. (2012). From uncertainty to robustness and system's resilience in ATM: a case study. In: Proceedings of the Third International Air Transport and Operations Symposium, Delft, Netherlands.

17. Holland, J. H. (2006). Studying Complex Adaptive Systems. Journal of Systems Science and Complexity, 19, 1-8.

18. Horonjeff, R., (1962), Planning and Design of Airports, First ed. McGraw Hill Book Company, New York.

19. Jim, H.K., Chang, Z.Y., (1998), An airport passenger terminal simulator: a planning and design tool. Simulation Practice and Theory 6 (4), 387-396

20. Ju, Y., Wang, A., Che, H., (2007), Simulation and optimization for the airport passenger flow. In: International Conference on Wireless Communications, Networking and Mobile Computing (WiCom), pp. 6605-6608.

21. Kim, B.-S., Lee, G.-G., Yoon, J.-Y., Kim, J.-J., Kim, W.-Y., (2008), A method of counting pedestrians in crowded scenes. ICIC 08. Springer-Verlag, Shanghai, China. pp. 1117-1126.

22. Koch, D.B., (2004), 3d visualization to support airport security operations. IEEE Aerospace and Electronic Systems Magazine 19 (6), 23-28.

23. Madas, M.A., Zografos, K.G. (2006). Airport slot allocation: from instruments to strategies. Journal of Air Transport Management 12 (2), 53-62.

24. Manataki, I.E., Zografos, K.G., (2009), A generic system dynamics based tool for airport terminal performance analysis. Transportation Research PartC: Emerging Technologies 17 (4), 428-443.

25. Manataki, I.E., Zografos, K.G., (2010), Assessing airport terminal performance using a system dynamics model. Journal of Air Transport Management 16 (2), 86-93.

26. Newell, G.F., (1971), Application of Queuing Theory. Chapman and Hall, London. Nie,

27. Odoni, A.R., de Neufville, R., (1992), Passenger terminal design. Transportation Research Part A: Policy and Practice 26 (1), 27-35.

28. Ohori, K., Kobayashi, N., Obata, A., Takahashi, A., Takahashi, S. (2012), Decision Support for Management of Agents' Knowledge and Skills with Job Rotation in Service-oriented Organization, 45th Hawaii International International Conference on Systems Science (HICSS-45 2012), Proceedings, 4-7 January, Grand Wailea, Maui, HI, USA 1492-1501

29. Ohori K., Yamane S., Kobayashi N., Obata A., Takahashi S. (2014) Agent-Based Social Simulation as an Aid to Communication Between Stakeholders. In: Chen SH., Terano T., Yamamoto R., Tai CC. (eds) Advances in Computational Social Science. Agent-Based Social Systems, vol 11. Springer, Tokyo

30. Schultz, M., \& Fricke, H. (2011). Managing passenger handling at airport terminals individual-based approach for modeling the stochastic passenger behavior. In Proceedings of the 9th USA/Europe Air Traffic Management Research and Development Seminar, ATM 2011 (pp. 438-447).

31. Takakuwa, S., Oyama, T. (2003). Modeling people flow: simulation analysis of international-departure passenger flows in an airport terminal. In: Winter Simulation Conference. New Orleans, Louisiana. pp. 1627-1634.

32. Tosic, V. (1992). A review of airport passenger terminal operations analysis and modelling. Transportation Research Part A: Policy and Practice 26 (1), 3-26.

33. Tosic, V., Babic, O., Janic, M. (1983). Airport passenger terminal simulation, Annals of Operations Research in Air Transportation, Faculty of Transport and Traffic Engineering, University of Belgrade. pp. 83-103.

34. Wu, P. P.-Y., Fookes, C., Pitchforth, J., \& Mengersen, K. (2015). A framework for model integration and holistic modelling of socio-technical systems. Decision Support Systems, 71, $14-27$. 
35. Wu, P. P.-Y., \& Mengersen, K. (2013). A review of models and model usage scenarios for an airport complex system. Transportation Research Part A: Policy and Practice, 47, 124 140 .

36. McDermott, T., Rouse, W., Goodman, S., \& Loper, M. (2013). Multi-level Modeling of Complex Socio-Technical Systems. Procedia Computer Science, 16, 1132-1141.

37. Park, H., Clear, T., Rouse, W. B., Basole, R. C., Braunstein, M. L., Brigham, K. L., \& Cunningham, L. (2012). Multilevel Simulations of Health Delivery Systems: A Prospective Tool for Policy, Strategy, Planning, and Management. Service Science, 4(3), 253-268. 